Published in final edited form as:

Curr Opin Microbiol. 2014 February ; 0: 32-37. doi:10.1016/j.mib.2013.11.004.

\title{
Staphylococcus aureus toxins
}

\author{
Michael Otto \\ Pathogen Molecular Genetics Section, Laboratory of Human Bacterial Pathogenesis, National \\ Institute of Allergy and Infectious Diseases, The National Institutes of Health, 9000 Rockville Pike, \\ Bethesda, Maryland 20892, USA, Phone : 3014435209 \\ Michael Otto: motto@niaid.nih.gov
}

\begin{abstract}
Staphylococcus aureus is a dangerous pathogen that causes a variety of severe diseases. The virulence of $S$. aureus is defined by a large repertoire of virulence factors, among which secreted toxins play a preeminent role. Many $S$. aureus toxins damage biological membranes, leading to cell death. In particular, S. aureus produces potent hemolysins and leukotoxins. Among the latter, some were recently identified to lyse neutrophils after ingestion, representing an especially powerful weapon against bacterial elimination by innate host defense. Furthermore, S. aureus secretes many factors that inhibit the complement cascade or prevent recognition by host defenses. Several further toxins add to this multi-faceted program of $S$. aureus to evade elimination in the host. This review will give an overview over $S$. aureus toxins focusing on recent advances in our understanding of how leukotoxins work in receptor-mediated or receptor-independent fashions.
\end{abstract}

\section{Introduction}

Staphylococcus aureus is a dangerous and versatile pathogen that can cause a multitude of different diseases. Most frequently, it causes skin infections and infections of the respiratory tract. Skin infections are usually community-acquired, whereas infections of the lung dominate among nosocomial S. aureus infections. Among nosocomial pathogens, S. aureus is the most common and associated with high morbidity and mortality. S. aureus pneumonia often develops in hospitalized patients with underlying conditions, such as in patients suffering from immune deficiencies or viral infections. However, S. aureus may also cause a variety of other sometimes very severe and life-threatening diseases, such as infective endocarditis, toxic shock syndrome, scalded skin syndrome, or osteomyelitis, to name but a few. Even necrotizing fasciitis and necrotizing pneumonia were reported with S. aureus as the causative agent $[1,2]$.

The versatility of $S$. aureus as a pathogen stems from the fact that $S$. aureus strains possess a varying repertoire of virulence factors, many of which are encoded on mobile genetic elements (MGEs), such as plasmids or prophages, and can be transferred between strains by horizontal gene transfer (HGT). HGT in S. aureus may happen via phage transduction, conjugation, or - as recently found - by direct uptake of "naked" DNA by genetic competence [3].

Many S. aureus virulence factors can be described as toxins. Toxins are usually defined as poisonous substances. Thus, the distinction from other virulence factors - molecules that

Publisher's Disclaimer: This is a PDF file of an unedited manuscript that has been accepted for publication. As a service to our customers we are providing this early version of the manuscript. The manuscript will undergo copyediting, typesetting, and review of the resulting proof before it is published in its final citable form. Please note that during the production process errors may be discovered which could affect the content, and all legal disclaimers that apply to the journal pertain. 
increase the potential of a pathogen to cause disease in a broader sense - is that they are secreted by the producing organism and interfere directly with the host. Toxins thus do not include molecules that, for example, combat mechanism of host defense in the intracellular space of the bacteria, such as intracellular reactive oxygen scavenging mechanisms. Also, $S$. aureus produces a large set of secreted, surface-bound proteins that enable the pathogen to attach to host tissue. Although this is an important mechanism of the $S$. aureus pathogenesis program, these surface-located proteins will not be regarded as toxins for the purpose of this review and the reader is referred to other reviews dealing specifically with those proteins [4]. Furthermore, molecules that are secreted but serve the defense from host immunity in a passive way, such as exopolymers with a function in providing resistance to antimicrobial peptides or leukocyte phagocytosis, will not be included here. Rather, this review will cover secreted $S$. aureus molecules that in some way or another directly harm the host. These are grouped in three categories: 1) membrane-damaging toxins, which may work in a receptormediated or receptor-independent fashion, 2) toxins that interfere with receptor function but are not membrane-damaging, and 3) secreted enzymes, such as those that degrade host molecules or affect important host defense mechanisms.

\section{Membrane-damaging toxins}

The cytoplasmic membrane is the target of a large series of bacterial toxins, including several that are produced by $S$. aureus. These toxins cause pore formation in the membrane, leading to the efflux of vital molecules and metabolites, and therefore are cytolytic. Two subgroups can be distinguished: those for which subsequent lysis is dependent on initial receptor interaction, and which thus show high target cell specificity, and those that interfere with membranes in a less specific fashion without receptor interaction (Fig. 1).

\section{Receptor-mediated}

S. aureus produces a variety of cytolytic toxins. Most are infamous for lysing red and/or white blood cells. Those that lyse red blood cells are called hemolysins, while those that target white blood cells are leukotoxins. Many cytolytic toxins of $S$. aureus have only recently been shown to require receptor interaction for their lytic function.

Alpha-toxin is probably the best-known toxin of $S$. aureus [5] and the first identified example of the beta-barrel forming toxins, which predominantly consist of beta sheets. It is lytic to red blood cells and a series of leukocytes, but not neutrophils [6]. It is 293 amino acids in length and forms a heptameric pore that leads to the efflux of mono- and, at higher concentration, divalent ions. At higher concentrations, pore formation may be receptorindependent, but pore formation at lower concentrations has recently been shown to be dependent on the interaction with the ADAM10 receptor [7,8]. Binding of alpha-toxin to ADAM10, a disintegrin and metalloproteinase, ultimately leads to the disruption of focal adhesions. In particular, cleavage of E-cadherin in epithelial cells leads to loss of epithelial barrier function. Independently, alpha-toxin also causes apoptosis in human monocytes, $\mathrm{T}$ and $\mathrm{B}$ cells [9].

S. aureus also produces are series of bi-component toxins that are structurally similar to alpha-toxin and belong to the beta-barrel pore-forming toxin family: the Panton-Valentine leukocidin (PVL, consisting of the LukS and LukF proteins), the leukocidins LukDE and LukAB (LukGH), and gamma-toxin (gamma-hemolysin, $\mathrm{HlgA}, \mathrm{HlgB}, \mathrm{HlgC}$ ). Intensified research has recently been prompted by the association of PVL with infections by community-associated methicillin-resistant $S$. aureus (CA-MRSA) strains [10], although the involvement of PVL in CA-MRSA disease remains controversial [11]. Initially often believed to function in a receptor-independent fashion, the discovery of the LukDE receptor (CCR5) [12], and the subsequent discoveries of the PVL and LukGH (LukAB) receptors 
(C5aR, C5L2 and CD11b, respectively) [13,14], clearly showed that these toxins require receptor interaction for cytolytic activity. Notably, these findings explained the often-noted species and target cell specificity of the bi-component S. aureus toxins [15].

\section{Non-receptor mediated}

In 2007, it was discovered that the long-known S. aureus delta-toxin (delta-hemolysin) is but one member of a family of secreted peptides called the phenol-soluble modulins (PSMs), which have multiple function in staphylococcal pathogenesis [16]. Importantly, some PSMs have pronounced, non-specific cytolytic activity. While members of the PSM family also occur in other, less pathogenic staphylococci [17], S. aureus produces high amounts of strongly cytolytic PSMs, in particular the PSMa peptides PSMa1 - a4 encoded in the psma locus, of which PSMa3 is by far the most active. PSMs trigger inflammatory responses by interaction with the FPR2 receptor, but their cytolytic activity is FPR2-independent [18]. They are small, amphipathic peptides with detergent-like properties. Accordingly, pores formed by delta-toxin are short-lived [19] and it can be assumed that other PSMs work similarly. According to a recent study that performed an alanine exchange peptide library screen with PSMa3, pro-inflammatory, cytolytic, and other properties of PSMs can be attributed to specific amino acid positions and different parts in the peptide [20]. Notably, similar to alpha-toxin and in contrast to many bi-component leukocidins, PSMs are produced by most $S$. aureus strains [16,21]. Only strains dysfunctional in the global virulence regulator Agr, which regulates most $S$. aureus toxins and exoenzymes, lack PSM production. Recently, PSMa peptides of $S$. aureus were identified as the toxins that contribute to neutrophil lysis after phagocytosis, a pathogenesis mechanism of immense importance for the high toxicity found in strongly aggressive S. aureus strains [22-24] (Fig. 2). Notably, lysis after phagocytosis might explain at least in part why the development of vaccines for $S$. aureus that work by enhancement of opsonophagocytosis failed so far [25]. Among the other leukocidins, only LukAB (LukGH) also lyses neutrophils after uptake $[26,27]$. Finally, recent work indicates that $\mathrm{S}$. aureus $\delta$-toxin contributes to the allergic skin disease atopic dermatitis by inducing mast cell degranulation [28]. Interestingly, only $\delta$ toxin but not PSMa peptides contributed to that phenotype, exemplifying that PSM peptides have undergone divergent evolution to fulfill different functions in pathogenesis.

\section{Toxins that interfere with receptor function (other than membrane- damaging)}

Enterotoxins are secreted toxins of $\sim 20$ to $30 \mathrm{kD}$ that interfere with intestine function and typically cause emesis and diarrhea [29]. They are superantigens, molecules that trigger $\mathrm{T}$ cell activation and proliferation without the need for antigen processing by allowing nonspecific interaction of the class II major histocompatibility complex MHC II with T cell receptors. S. aureus strains can produce a wide array $(\sim 20)$ of enterotoxins and enterotoxinlike toxins. Enterotoxins, also produced by some other bacteria, share a common structure comprising a two-domain fold, a long central alpha-helix, the characteristic N-terminal "oligosaccharide/oligonucleotide fold" with beta-barrel structure and a C-terminal "beta grasp" motif. The mechanisms by which staphylococcal enterotoxins work are not well known, but may include the activation of cytokine release, ultimately causing cell death by apoptosis [30]. Staphylococcal enterotoxin B (SEB) is considered a biological warfare weapon [31]. Staphylococcal enterotoxin C (SEC) has been shown to promote infective endocarditis, sepsis, and kidney injury in the CA-MRSA strain MW2 [32].

The most famous $S$. aureus superantigen, the 22-kD toxic shock syndrome toxin (TSST), causes toxic shock syndrome (TSS) by stimulating release of IL-1, IL-2, TNF-a, and other cytokines. TSS is a severe and potentially fatal disease mostly known for the outbreak 
associated with tampon use in the 1980s. In contrast to the enterotoxin superantigens, TSST does not cause emesis. With the exception of SelX, a recently described core genome encoded enterotoxin produced by $95 \%$ of isolates, all enterotoxins and TSST are present in only a small number of $S$. aureus strains [33].

S. aureus produces a series of secreted proteins that interfere with leukocyte receptors to evade recognition and prevent subsequent activation of the immune system. CHIPS (chemotaxis inhibitory protein of S. aureus) binds specifically to the C5aR and FPR receptors, thereby impairing the recognition of bacterial formylated peptides by FPR and blocking activation of leukocytes via C5a, a terminal effector of the complement system [34]. FLIPr (FPR-like 1 inhibitory protein) and its homologue FLIPr-like also block recognition of formylated peptides by the FPR receptor, with FLIPr-like having $\sim 100$ times more potency [35,36]. Additionally, FLIPr is an efficient antagonist of FPR2 (formerly named FPRL1), which is the receptor recognizing S. aureus PSM peptides. Finally, both FLIPr and FLIPr-like have recently been demonstrated to competitively block IgG-ligand binding by Fc $\gamma \mathrm{R}$ receptors, inhibiting neutrophil phagocytosis and subsequent killing of $S$. aureus [37]. CHIPS, FLIPr and FLIPR-like are encoded within pathogenicity islands, but show relatively high frequency among $S$. aureus isolates.

\section{Enzymes}

Many secreted $S$. aureus enzymes degrade host molecules or interfere with host metabolic or signaling cascades. Several of those are proteases. Relatively non-specific proteases degrade host proteins in a broad fashion, leading to tissue destruction, but may also have a more specific impact. The protease aureolysin ( $S$. aureus neutral proteinase) cleaves many proteins including insulin $\mathrm{B}$, with a preference of cleaving after hydrophobic residues. Furthermore, aureolysin inactivates PSMs, thus having a major impact on the pathogenesis of osteomyelitis [38]. It also leads to maturation of another non-specific S. aureus exoprotease, the glutamyl endopeptidase SspA, which cleaves after glutamate residues. Aureolysin, glutamyl endopeptidase, and the cysteine proteases staphopain A and B all interfere with complement factors, leading to evasion of complement-mediated bacterial killing [39]. The biological function of further $S$. aureus proteases, a series of serine proteases, is not well understood, except for the exfoliative toxin serine proteases. The exfoliative toxins specifically cleave desmosomal cadherins of the superficial skin layers [40], leading to staphylococcal scalded skin syndrome (SSSS), a severe skin disease presenting with rash, blisters, and severe lesional damage of the skin. Finally, S. aureus may produce a protease that degrades collagen, called collagenase.

Staphylokinase activates plasminogen to plasmin, which degrades fibrin clots. The biological significance of this activity is to diminish the function of the fibrin meshwork in keeping a staphylococcal infection localized. It also cleaves the complement factor $\mathrm{C} 3 \mathrm{~b}$ [41], adding to the broad attack of other staphylococcal proteases and further molecules, such as the fibrinogen-binding protein Efb and SCIN (staphylococcal complement inhibitor) $[42,43]$, on complement function. While staphylokinase facilitates bacterial penetration through the skin barrier, it decreases the severity of skin infections by leading to drainage [44].

S. aureus produces two coagulases, staphylocoagulase and von Willebrand factor (vWF), which contribute to the formation of fibrin clots after binding to prothrombin (forming a complex called staphylothrombin) and several other plasma proteins, thereby triggering the conversion of fibrinogen to fibrin [45]. This leads to fibrin clots on the surface of S. aureus cells, inhibiting phagocytosis, causing abscess formation [46] and adhesion of S. aureus to catheters during biofilm-associated infection [47]. 
S. aureus beta-toxin is a sphingomyelinase of type $\mathrm{C}$ that degrades the sphingomyelin present on the surface of a variety of host cells, leading to cell lysis. In many virulent $S$. aureus strains, the gene encoding beta-toxin $(h l b)$ is disrupted by a pathogenicity island [48]. Beta-toxin is thus not considered a virulence factor contributing significantly to the pathogenicity of virulent $S$. aureus.

Finally, S. aureus produces lipases and nucleases, whose functions in pathogenesis are poorly understood. Possibly, nucleases may decrease the antibacterial activity of neutrophil extracellular traps (NETs), which consist of DNA released from lysed neutrophils [49].

\section{Other toxins}

Some $S$. aureus secreted host-damaging factors cannot be classified in the categories used in this review. These include the abovementioned Efb and SCIN, which are potent inhibitors of the function of convertase $\mathrm{C} 3$, a crucial enzyme in the complement pathway.

\section{Conclusions}

Main developments in recent $S$. aureus toxin research include the discovery of (i) the PSMs, (ii) a large series of complement-inhibiting factors, (iii) molecules that block recognition by host immune cells, and the finding that leukotoxins and alpha-toxin bind to specific receptors. These findings and discoveries will prompt further research in those areas, aimed to investigate for example the exact mechanisms by which PSMa peptides and specific leukotoxins cause cell death and phagosomal escape.

\section{Acknowledgments}

This work was supported by the Intramural Research Program of the National Institute of Allergy and Infectious Diseases (NIAID), U.S. National Institutes of Health (NIH).

\section{References and recommended reading}

Papers of particular interest, published within the period of review, have been highlighted as:

- of special interest

•• of outstanding interest

1. Francis JS, Doherty MC, Lopatin U, Johnston CP, Sinha G, Ross T, Cai M, Hansel NN, Perl T, Ticehurst JR, et al. Severe community-onset pneumonia in healthy adults caused by methicillinresistant Staphylococcus aureus carrying the Panton-Valentine leukocidin genes. Clin Infect Dis. 2005; 40:100-107. [PubMed: 15614698]

2. Miller LG, Perdreau-Remington F, Rieg G, Mehdi S, Perlroth J, Bayer AS, Tang AW, Phung TO, Spellberg B. Necrotizing fasciitis caused by community-associated methicillin-resistant Staphylococcus aureus in Los Angeles. N Engl J Med. 2005; 352:1445-1453. [PubMed: 15814880]

3. Morikawa K, Takemura AJ, Inose Y, Tsai M, Nguyen Thi le T, Ohta T, Msadek T. Expression of a cryptic secondary sigma factor gene unveils natural competence for DNA transformation in Staphylococcus aureus. PLoS Pathog. 2012; 8:e1003003. [PubMed: 23133387]

4. Heilmann C. Adhesion mechanisms of staphylococci. Adv Exp Med Biol. 2011; 715:105-123. [PubMed: 21557060]

5. Berube BJ, Bubeck Wardenburg J. Staphylococcus aureus alpha-toxin: nearly a century of intrigue. Toxins (Basel). 2013; 5:1140-1166. [PubMed: 23888516] 
6. Valeva A, Walev I, Pinkernell M, Walker B, Bayley H, Palmer M, Bhakdi S. Transmembrane betabarrel of staphylococcal alpha-toxin forms in sensitive but not in resistant cells. Proc Natl Acad Sci U S A. 1997; 94:11607-11611. [PubMed: 9326657]

•7. Inoshima I, Inoshima N, Wilke GA, Powers ME, Frank KM, Wang Y, Bubeck Wardenburg J. A Staphylococcus aureus pore-forming toxin subverts the activity of ADAM10 to cause lethal infection in mice. Nat Med. 2011; 17:1310-1314. This study describes how interaction of alphatoxin with the ADAM10 receptor leads to exacerbation of S. aureus infection. [PubMed: 21926978]

8. Wilke GA, Bubeck Wardenburg J. Role of a disintegrin and metalloprotease 10 in Staphylococcus aureus alpha-hemolysin-mediated cellular injury. Proc Natl Acad Sci U S A. 2010; 107:1347313478. [PubMed: 20624979]

9. Nygaard TK, Pallister KB, DuMont AL, DeWald M, Watkins RL, Pallister EQ, Malone C, Griffith S, Horswill AR, Torres VJ, et al. Alpha-toxin induces programmed cell death of human T cells, B cells, and monocytes during USA300 infection. PLoS ONE. 2012; 7:e36532. [PubMed: 22574180]

10. Vandenesch F, Naimi T, Enright MC, Lina G, Nimmo GR, Heffernan H, Liassine N, Bes M, Greenland T, Reverdy ME, et al. Community-acquired methicillin-resistant Staphylococcus aureus carrying Panton-Valentine leukocidin genes: worldwide emergence. Emerg Infect Dis. 2003; 9:978-984. [PubMed: 12967497]

11. Otto M. Basis of virulence in community-associated methicillin-resistant Staphylococcus aureus. Annu Rev Microbiol. 2010; 64:143-162. [PubMed: 20825344]

$\bullet$ 12. Alonzo F 3rd, Kozhaya L, Rawlings SA, Reyes-Robles T, DuMont AL, Myszka DG, Landau NR, Unutmaz D, Torres VJ. CCR5 is a receptor for Staphylococcus aureus leukotoxin ED. Nature. 2013; 493:51-55. In this study, a recptor for an S. aureus leokotoxin was described for the first time. [PubMed: 23235831]

13. DuMont AL, Yoong P, Day CJ, Alonzo F 3rd, McDonald WH, Jennings MP, Torres VJ. Staphylococcus aureus LukAB cytotoxin kills human neutrophils by targeting the CD11b subunit of the integrin Mac-1. Proc Natl Acad Sci U S A. 2013; 110:10794-10799. [PubMed: 23754403]

-14. Spaan AN, Henry T, van Rooijen WJ, Perret M, Badiou C, Aerts PC, Kemmink J, de Haas CJ, van Kessel KP, Vandenesch F, et al. The staphylococcal toxin Panton-Valentine Leukocidin targets human C5a receptors. Cell Host Microbe. 2013; 13:584-594. This study describes the receptor(s) for the leukotoxin PVL. [PubMed: 23684309]

15. Loffler B, Hussain M, Grundmeier M, Bruck M, Holzinger D, Varga G, Roth J, Kahl BC, Proctor RA, Peters G. Staphylococcus aureus panton-valentine leukocidin is a very potent cytotoxic factor for human neutrophils. PLoS Pathog. 2010; 6:e1000715. [PubMed: 20072612]

16. Wang R, Braughton KR, Kretschmer D, Bach TH, Queck SY, Li M, Kennedy AD, Dorward DW, Klebanoff SJ, Peschel A, et al. Identification of novel cytolytic peptides as key virulence determinants for community-associated MRSA. Nat Med. 2007; 13:1510-1514. [PubMed: 17994102]

17. Rautenberg M, Joo HS, Otto M, Peschel A. Neutrophil responses to staphylococcal pathogens and commensals via the formyl peptide receptor 2 relates to phenol-soluble modulin release and virulence. Faseb J. 2011; 25:1254-1263. [PubMed: 21183593]

18. Kretschmer D, Gleske AK, Rautenberg M, Wang R, Koberle M, Bohn E, Schoneberg T, Rabiet MJ, Boulay F, Klebanoff SJ, et al. Human formyl peptide receptor 2 senses highly pathogenic Staphylococcus aureus. Cell Host Microbe. 2010; 7:463-473. [PubMed: 20542250]

19. Talbot JC, Thiaudiere E, Vincent M, Gallay J, Siffert O, Dufourcq J. Dynamics and orientation of amphipathic peptides in solution and bound to membranes: a steady-state and time-resolved fluorescence study of staphylococcal delta-toxin and its synthetic analogues. Eur Biophys J. 2001; 30:147-161. [PubMed: 11409466]

20. Cheung GY, Kretschmer D, Queck SY, Joo HS, Wang R, Duong AC, Nguyen TH, Bach TH, Porter AR, DeLeo FR, et al. Insight into structure-function relationship in phenol-soluble modulins using an alanine screen of the phenol-soluble modulin (PSM) alpha3 peptide. Faseb J. 2013 Epub. In press.

21. Li M, Diep BA, Villaruz AE, Braughton KR, Jiang X, DeLeo FR, Chambers HF, Lu Y, Otto M. Evolution of virulence in epidemic community-associated methicillin-resistant Staphylococcus aureus. Proc Natl Acad Sci U S A. 2009; 106:5883-5888. [PubMed: 19293374] 
22. Chatterjee SS, Joo HS, Duong AC, Dieringer TD, Tan VY, Song Y, Fischer ER, Cheung GYC, Li M, Otto M. Essential Staphylococcus aureus toxin export system. Nat Med. 2013; 19:364-367. [PubMed: 23396209]

-23. Surewaard B, de Haas C, Vervoort F, Rigby K, Deleo F, Otto M, van Strijp J, Nijland R. Staphylococcal alpha-Phenol Soluble Modulins contribute to neutrophil lysis after phagocytosis. Cell Microbiol. 2013; 15:1427-1437. This study shows that PSMa peptides have the capacity to lyse neutrophils after uptake. [PubMed: 23470014]

-24. Geiger T, Francois P, Liebeke M, Fraunholz M, Goerke C, Krismer B, Schrenzel J, Lalk M, Wolz C. The stringent response of Staphylococcus aureus and its impact on survival after phagocytosis through the induction of intracellular PSMs expression. PLoS Pathog. 2012; 8:e1003016. This study shows that the primary regulatory mechanism leading to PSM-mediated survival of $S$. aureus after phagocytosis is the stringent response. [PubMed: 23209405]

25. DeLeo FR, Otto M. An antidote for Staphylococcus aureus pneumonia? J Exp Med. 2008; 205:271-274. [PubMed: 18268043]

26. Ventura CL, Malachowa N, Hammer CH, Nardone GA, Robinson MA, Kobayashi SD, DeLeo FR. Identification of a novel Staphylococcus aureus two-component leukotoxin using cell surface proteomics. PLoS ONE. 2010; 5:e11634. [PubMed: 20661294]

27. DuMont AL, Yoong P, Surewaard BG, Benson MA, Nijland R, van Strijp JA, Torres VJ. Staphylococcus aureus elaborates leukocidin $\mathrm{AB}$ to mediate escape from within human neutrophils. Infect Immun. 2013; 81:1830-1841. [PubMed: 23509138]

28. Nakamura Y, Oscherwitz J, Cease KB, Chan SM, Munoz-Planillo R, Hasegawa M, Villaruz AE, Cheung GY, McGavin MJ, Otto M, et al. Staphylococcus $\delta$-toxin promotes allergic skin disease by inducing mast cell degranulation. Nature. 2013 In press.

29. Hennekinne JA, De Buyser ML, Dragacci S. Staphylococcus aureus and its food poisoning toxins: characterization and outbreak investigation. FEMS Microbiol Rev. 2012; 36:815-836. [PubMed: 22091892]

30. Lin CF, Chen CL, Huang WC, Cheng YL, Hsieh CY, Wang CY, Hong MY. Different types of cell death induced by enterotoxins. Toxins (Basel). 2010; 2:2158-2176. [PubMed: 22069678]

31. Zapor M, Fishbain JT. Aerosolized biologic toxins as agents of warfare and terrorism. Respir Care Clin N Am. 2004; 10:111-122. [PubMed: 15062231]

32. Salgado-Pabon W, Breshears L, Spaulding AR, Merriman JA, Stach CS, Horswill AR, Peterson ML, Schlievert PM. Superantigens are critical for Staphylococcus aureus infective endocarditis, sepsis, and acute kidney injury. mBio. 2013:4.

33. Wilson GJ, Seo KS, Cartwright RA, Connelley T, Chuang-Smith ON, Merriman JA, Guinane CM, Park JY, Bohach GA, Schlievert PM, et al. A novel core genome-encoded superantigen contributes to lethality of community-associated MRSA necrotizing pneumonia. PLoS Pathog. 2011; 7:e1002271. [PubMed: 22022262]

34. de Haas CJ, Veldkamp KE, Peschel A, Weerkamp F, Van Wamel WJ, Heezius EC, Poppelier MJ, Van Kessel KP, van Strijp JA. Chemotaxis inhibitory protein of Staphylococcus aureus, a bacterial antiinflammatory agent. J Exp Med. 2004; 199:687-695. [PubMed: 14993252]

35. Prat C, Haas PJ, Bestebroer J, de Haas CJ, van Strijp JA, van Kessel KP. A homolog of formyl peptide receptor-like 1 (FPRL1) inhibitor from Staphylococcus aureus (FPRL1 inhibitory protein) that inhibits FPRL1 and FPR. J Immunol. 2009; 183:6569-6578. [PubMed: 19846866]

36. Prat C, Bestebroer J, de Haas CJ, van Strijp JA, van Kessel KP. A new staphylococcal antiinflammatory protein that antagonizes the formyl peptide receptor-like 1. J Immunol. 2006; 177:8017-8026. [PubMed: 17114475]

37. Stemerding AM, Kohl J, Pandey MK, Kuipers A, Leusen JH, Boross P, Nederend M, Vidarsson G, Weersink AY, van de Winkel JG, et al. Staphylococcus aureus formyl peptide receptor-like 1 inhibitor (FLIPr) and its homologue FLIPr-like are potent FcgammaR antagonists that inhibit IgGmediated effector functions. J Immunol. 2013; 191:353-362. [PubMed: 23740955]

38. Cassat JE, Hammer ND, Campbell JP, Benson MA, Perrien DS, Mrak LN, Smeltzer MS, Torres VJ, Skaar EP. A secreted bacterial protease tailors the Staphylococcus aureus virulence repertoire to modulate bone remodeling during osteomyelitis. Cell Host Microbe. 2013; 13:759-772.

[PubMed: 23768499] 
39. Jusko M, Potempa J, Kantyka T, Bielecka E, Miller HK, Kalinska M, Dubin G, Garred P, Shaw LN, Blom AM. Staphylococcal proteases aid in evasion of the human complement system. J Innate Immun. 2013 Epub. In press.

40. Bukowski M, Wladyka B, Dubin G. Exfoliative toxins of Staphylococcus aureus. Toxins (Basel). 2010; 2:1148-1165. [PubMed: 22069631]

41. Rooijakkers SH, van Wamel WJ, Ruyken M, van Kessel KP, van Strijp JA. Anti-opsonic properties of staphylokinase. Microbes Infect. 2005; 7:476-484. [PubMed: 15792635]

42. Hammel M, Sfyroera G, Ricklin D, Magotti P, Lambris JD, Geisbrecht BV. A structural basis for complement inhibition by Staphylococcus aureus. Nat Immunol. 2007; 8:430-437. [PubMed: 17351618]

43. Jongerius I, Kohl J, Pandey MK, Ruyken M, van Kessel KP, van Strijp JA, Rooijakkers SH. Staphylococcal complement evasion by various convertase-blocking molecules. J Exp Med. 2007; 204:2461-2471. [PubMed: 17893203]

44. Kwiecinski J, Jacobsson G, Karlsson M, Zhu X, Wang W, Bremell T, Josefsson E, Jin T. Staphylokinase promotes the establishment of Staphylococcus aureus skin infections while decreasing disease severity. J Infect Dis. 2013; 208:990-999. [PubMed: 23801604]

45. Thomer L, Schneewind O, Missiakas D. Multiple ligands of von Willebrand Factor binding protein (vWbp) promote Staphylococcus aureus clot formation in human plasma. J Biol Chem. 2013 In press.

46. Cheng AG, McAdow M, Kim HK, Bae T, Missiakas DM, Schneewind O. Contribution of coagulases towards Staphylococcus aureus disease and protective immunity. PLoS Pathog. 2010; 6:e1001036. [PubMed: 20700445]

47. Vanassche T, Peetermans M, Van Aelst LN, Peetermans WE, Verhaegen J, Missiakas DM, Schneewind O, Hoylaerts MF, Verhamme P. The role of staphylothrombin-mediated fibrin deposition in catheter-related Staphylococcus aureus infections. J Infect Dis. 2013; 208:92-100. [PubMed: 23532100]

48. Novick RP, Schlievert P, Ruzin A. Pathogenicity and resistance islands of staphylococci. Microbes Infect. 2001; 3:585-594. [PubMed: 11418332]

49. Brinkmann V, Zychlinsky A. Neutrophil extracellular traps: is immunity the second function of chromatin? J Cell Biol. 2012; 198:773-783. [PubMed: 22945932] 


\section{Highlights}

- S. aureus produces a wide variety of toxins mostly aimed to evade elimination by host defenses.

- Many S. aureus toxins are encoded on mobile genetic elements, leading to a strongly varying repertoire of toxins in different isolates.

- Some toxins, such as alpha-toxin and PSMs, are produced by virtually all strains, representing an $S$. aureus toxin "core set".

- Classical leukotoxins of S. aureus work in a receptor-mediated, while PSMs lyse in a receptor-independent fashion.

- The leukotoxin LukAB (LukGH) and PSMs can lyse after phagocytosis. 


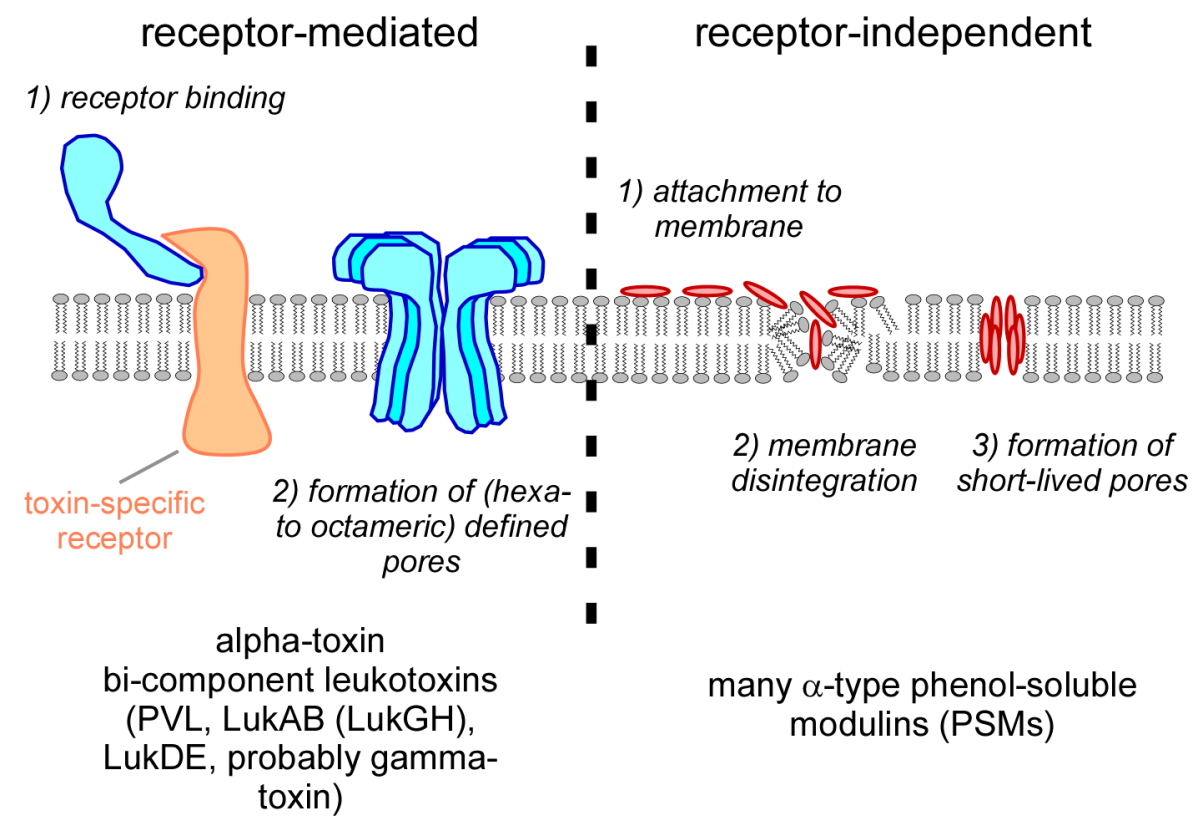

Fig. 1.

Membrane-damaging toxins. Alpha-toxin and the bi-component leukotoxins of S. aureus bind to specific receptors, upon which formation of a defined pore occurs. Receptors have been identified for alpha-toxin, PVL, LukAB (LukGH), and LukDE. Probably gamma-toxin also binds to a specific receptor. PSMs are believed to attach to the cytoplasmic membrane in a non-specific fashion and lead to membrane disintegration. Probably the phospholipid composition and membrane charge are important for cell susceptibility to PSMs. Pores formed by PSMs are likely short-lived, as shown for delta-toxin. 


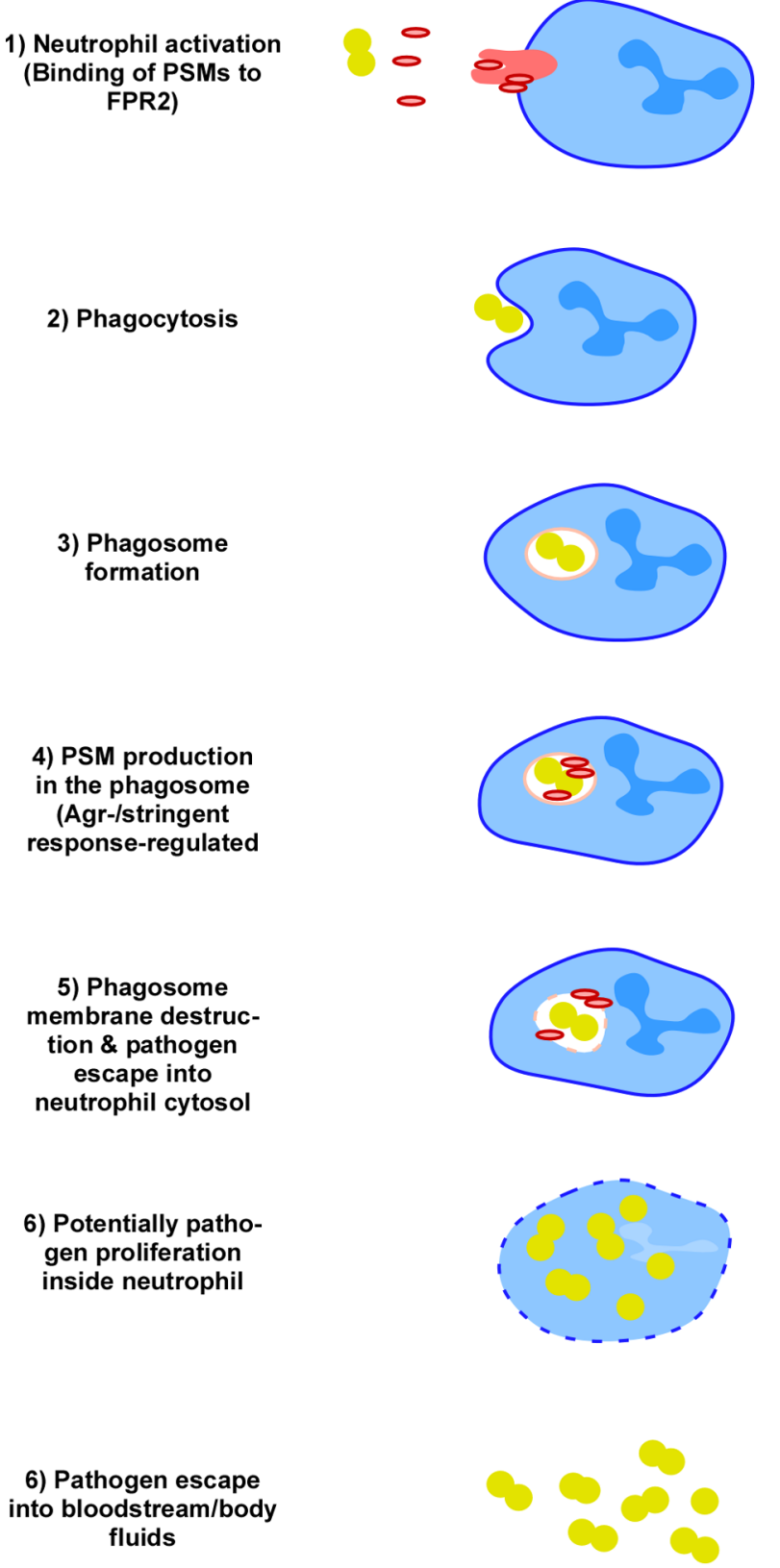

Fig. 2.

Neutrophil lysis after phagocytosis. Lysis after phagocytosis from within the neutrophil phagosome was demonstrated for $S$. aureus PSMa peptides and the leukotoxin LukAB (LukGH), illustrated here for PSMs. PSMs trigger neutrophil activation by interaction with the FPR2 receptor. After phagocytosis and phagosome formation, bacterial regulatory systems (Agr, stringent response) lead to PSM production and PSM-mediated phagosome lysis. Bacteria may further proliferate in the neutrophil. Upon ultimate neutrophil destruction the bacteria escape from the cell. 